Provided for non-commercial research and education use. Not for reproduction, distribution or commercial use.

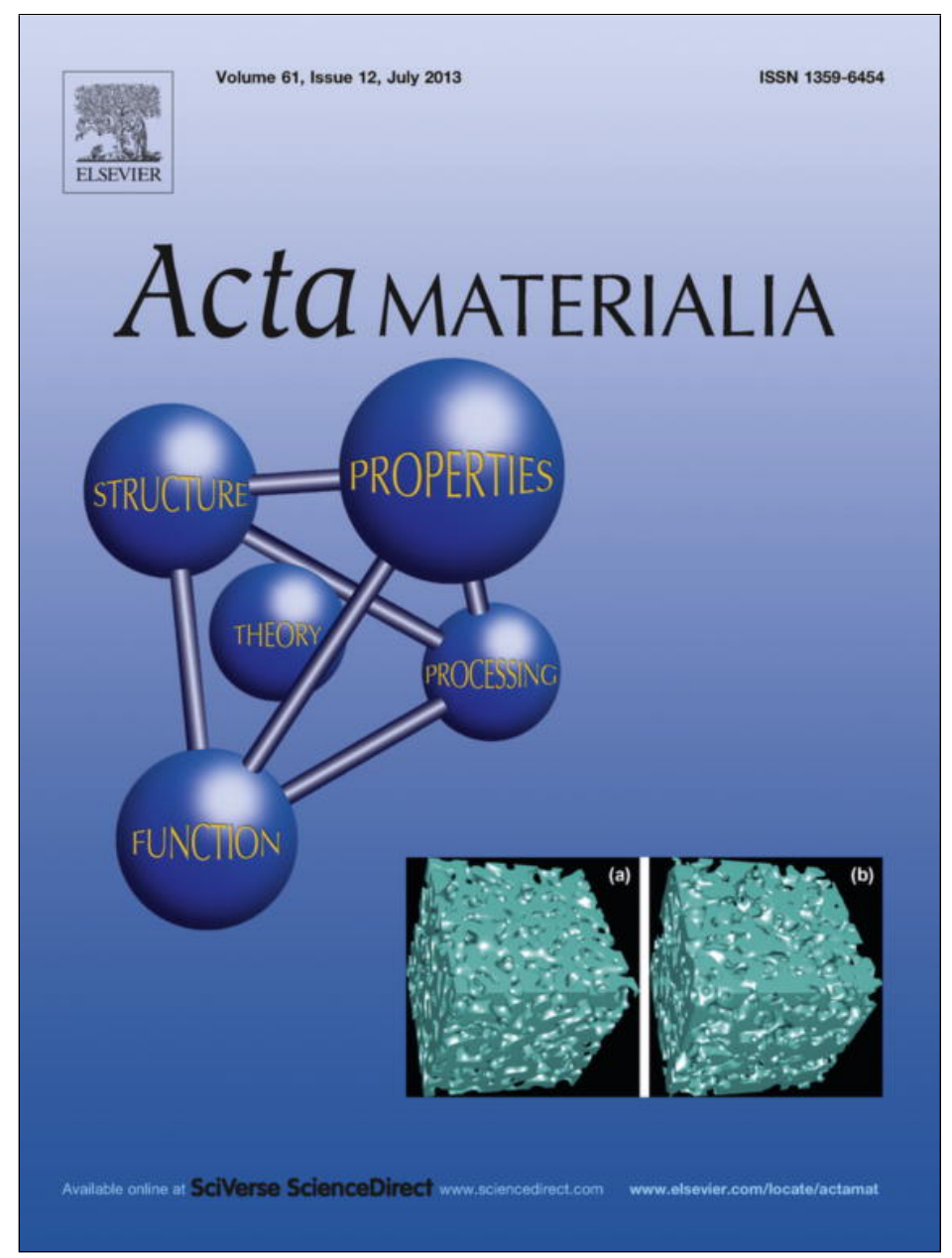

This article appeared in a journal published by Elsevier. The attached copy is furnished to the author for internal non-commercial research and education use, including for instruction at the authors institution and sharing with colleagues.

Other uses, including reproduction and distribution, or selling or licensing copies, or posting to personal, institutional or third party websites are prohibited.

In most cases authors are permitted to post their version of the article (e.g. in Word or Tex form) to their personal website or institutional repository. Authors requiring further information regarding Elsevier's archiving and manuscript policies are encouraged to visit:

http://www.elsevier.com/authorsrights 


\title{
Local melting in silicon driven by retrograde solubility
}

\author{
D.P. Fenning ${ }^{\text {a,* }}$, B.K. Newman ${ }^{\text {a,1 }}$, M.I. Bertoni ${ }^{a, 2}$, S. Hudelson ${ }^{\text {a,3 }}$, S. Bernardis ${ }^{\text {a }}$, \\ M.A. Marcus ${ }^{b}$, S.C. Fakra ${ }^{b}$, T. Buonassisi ${ }^{a}$ \\ ${ }^{\mathrm{a}}$ Massachusetts Institute of Technology, Cambridge, MA 02139, USA \\ b Advanced Light Source, Lawrence Berkeley National Laboratory, Berkeley, CA 94720, USA
}

Received 21 September 2012; received in revised form 18 March 2013; accepted 23 March 2013

Available online 20 May 2013

\begin{abstract}
High point-defect enthalpy of formation leads to retrograde solubility for a number of solutes in silicon, especially $d$-shell transition metals. We present direct experimental evidence for a thermodynamic pathway leading to local retrograde melting in silicon driven by the retrograde solubility of low-concentration metallic solutes at temperatures above the bounding liquid-silicide-silicon invariant reaction. We experimentally demonstrate this local melting pathway using in situ synchrotron-based X-ray microprobe measurements of silicon supersaturated with nickel, wherein solute precipitation into liquid droplets is observed. No significant energy barrier is observed for the nucleation of the liquid droplets at the surface, suggesting that in the $\mathrm{Ni}-\mathrm{Si}$ system, retrograde melting will occur upon supersaturation if favorable heterogeneous nucleation sites are available.
\end{abstract}

(C) 2013 Acta Materialia Inc. Published by Elsevier Ltd. All rights reserved.

Keywords: Silicon; Nickel; Precipitation; Retrograde melting; Melting

\section{Introduction}

Predictive control of the concentration and distribution of metal impurities in semiconductors is essential to producing high-quality integrated circuit, solar cell thermoelectric and micro/nanostructured devices [1-3]. The development of micron-scale in situ characterization tools, including in situ synchrotron-based X-ray microprobes [4$6]$, enables the study of impurities at industrially relevant temperatures close to semiconductor crystal growth and device processing temperatures.

\footnotetext{
* Corresponding author. Tel.: +16173245130.

E-mail addresses: dfenning@alum.mit.edu (D.P. Fenning), buonassisi@mit.edu (T. Buonassisi).

${ }^{1}$ Current address: Center for Nanophotonics, FOM Institute AMOLF, Amsterdam, Netherlands.

${ }^{2}$ Current address: Department of Electrical, Computer and Energy Engineering, Arizona State University, Tempe, AZ, USA.

${ }^{3}$ Current address: 1366 Technologies, 6 Preston Ct, Bedford, MA 01730, USA.
}

One such high-temperature impurity-semiconductor interaction, retrograde melting, or melting during cooling, has been observed in semiconductor systems including antimony telluride $\left(\mathrm{Sb}_{2} \mathrm{Te}_{3}\right)$ [7] and silicon [6]. The latter work describes retrograde melting in a $\mathrm{Cu}-\mathrm{Fe}-\mathrm{Ni}-\mathrm{Si}$ system in which all impurity species exhibit retrograde solubility in silicon, where the temperature of maximum solid solubility occurs above the temperature of the bounding invariant reaction (eutectic for $\mathrm{Fe}$ and $\mathrm{Cu}$, peritectic for $\mathrm{Ni}$ ) $[8,9]$. Retrograde melting is not typically discussed in the context of silicon manufacturing, but the effect has been used to seed microwires on a semiconductor surface [10], and may be partially responsible for the local accumulation of multiple metal species in as-grown multicrystalline silicon ingot material [6,11-14]. Indeed, any silicon sample containing impurity concentrations above the solid solubility of the invariant reaction temperature would enter the region of retrograde solubility during cool down from crystallization, potentially leading to local retrograde melting. For example, this corresponds to concentrations of iron above $\sim 10^{17} \mathrm{~cm}^{-3}$, copper above $\sim 6 \times 10^{16} \mathrm{~cm}^{-3}$ or nickel 
above $\sim 2 \times 10^{17} \mathrm{~cm}^{-3}$ [9]. Iron and copper concentrations exceeding these values have been measured at the top of contaminated multicrystalline ingots [15], while in the deteriorated "red" zone area near the crucible wall iron concentrations approach these values [16].

However, the precise conditions that lead to retrograde melting in silicon have not been verified previously. Here, we examine local retrograde melting in the binary $\mathrm{Ni}-\mathrm{Si}$ system, because $\mathrm{Ni}$ is known to exhibit retrograde solubility in silicon and has a distinctive transition in near-edge Xray absorption between the high-temperature liquid $\mathrm{Ni}-\mathrm{Si}$ phase and the solid $\mathrm{NiSi}_{2}$ phase in equilibrium with $\mathrm{Si}$ [6].

Our hypothesized local melting pathway for $\mathrm{Ni}$ in $\mathrm{Si}$ is shown on a schematic phase diagram of the Si-rich side of the Ni-Si binary system in Fig. 1. The pathway proceeds as follows. (1) A highly Ni-contaminated ( $\gtrsim 2-3 \times 10^{17}-$ $\mathrm{cm}^{-3}$ ) Si sample is heated to a temperature at or above the solvus line. (2) The sample is then cooled, and the resulting supersaturation due to the retrograde solubility of $\mathrm{Ni}$ in $\mathrm{Si}$ forces precipitation. Because the sample temperature remains above the $\mathrm{Ni}-\mathrm{Si}$ peritectic, $T_{\text {per }}$, the resulting $\mathrm{Ni}$ rich precipitates are a liquid $\mathrm{Ni}-\mathrm{Si}$ phase (shown by red triangles). (3) After cooling below the peritectic temperature, the precipitates solidify into $\mathrm{NiSi}_{2}$.

Previously, the formation of $\mathrm{NiSi}_{2}$ in $\mathrm{Si}$ substrates has been widely studied using ex situ methods to examine the results of annealing treatments. Studies of nickel silicide formation on the $\mathrm{Si}$ (111) surface have revealed both aligned (A-type) and twinned (B-type) crystal orientations to be favorable $[17,18]$. Extended moderate-temperature annealing treatments aimed at developing thermodynamically stable conditions within the bulk have demonstrated

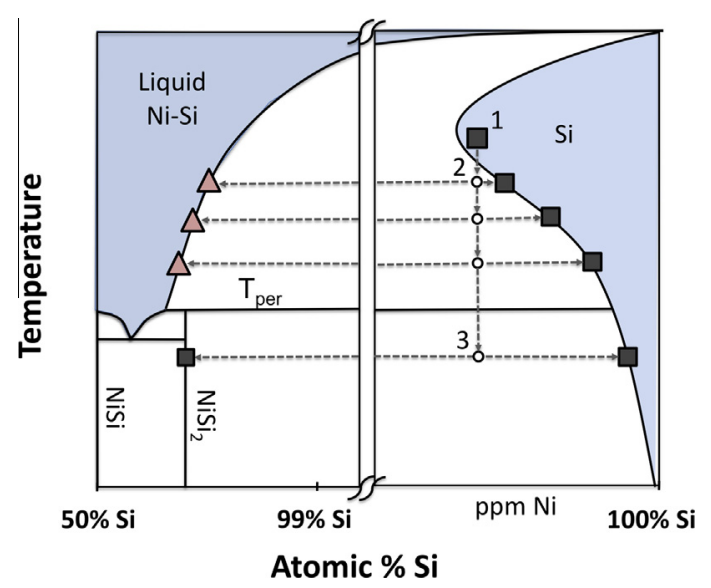

Fig. 1. A schematic diagram of the hypothesized local melting pathway for $\mathrm{Ni}$ in $\mathrm{Si}$ is shown. Solid states are shown as black squares, liquid states as red triangles, and the trace of the isoconcentration line in the two-phase region is shown as small open circles. The local melting pathway starts with $\mathrm{Ni}$ in a fully dissolved state at (1), then cooling leads to a two-phase state consisting of liquid Ni-Si droplets in the Si matrix at (2), until finally the temperature drops below the peritectic temperature, and (3) and the precipitates solidify into $\mathrm{NiSi}_{2}$. (For interpretation of the references to colour in this figure legend, the reader is referred to the web version of this article.) that $\mathrm{NiSi}_{2}$ precipitates readily decorate available structural defects in $\mathrm{Si}[19,20]$, often forming tetrahedral or octahedral particles bounded by $\{111\}$ faces of both aligned and twinned types [21,22]. Quenching from high temperatures has been used as a means to investigate early-stage precipitation, with high-resolution transmission electron microscopy revealing $\mathrm{NiSi}_{2}$ platelets consisting of only two $\left\{\begin{array}{llll}1 & 1 & 1\end{array}\right\}$ planes [23]. Interactions above the Ni-Si peritectic at $993{ }^{\circ} \mathrm{C}$ have also been studied by $\mathrm{Li}$ et al. [24] who inferred liquid $\mathrm{Ni}-\mathrm{Si}$ formation from the morphology of particles formed after quenching a sample with a $\mathrm{Ni}$ film on a Si substrate after annealing at $1200^{\circ} \mathrm{C}$.

In this contribution, we investigate $\mathrm{Ni}$ precipitation in $\mathrm{Si}$ at temperatures ranging from 800 to $1225^{\circ} \mathrm{C}$ using in situ measurements at a synchrotron-based X-ray microprobe. Using a combination of in situ X-ray fluorescence and absorption spectroscopy, we trace the thermodynamic pathway of retrograde melting in Ni-contaminated $\mathrm{Si}$ and confirm that melting occurs when retrograde solubility and local supersaturation are present. Ni precipitates first as microscopic liquid droplets in samples that supersaturate during cooling in the region of retrograde solubility, and then upon further cooling these droplets solidify into $\mathrm{NiSi}_{2}$ particles. No significant energy barrier for liquid droplet precipitation in the $\mathrm{Ni}-\mathrm{Si}$ system is observed, but an energy barrier for the solidification of these microscopic droplets into solid $\mathrm{NiSi}_{2}$ particles is found.

\section{Thermodynamic framework for retrograde melting}

When discussing retrograde melting, we must be in a temperature regime above the bounding invariant reaction in the binary system (e.g. binary eutectic or peritectic temperature) but below the Si melting temperature. At these temperatures, the solvus line separates the Si phase from the two-phase field consisting of liquid impurity-Si and solid $\mathrm{Si}$, as can be seen from binary phase diagrams [25]. A high enthalpy of impurity point-defect formation causes a low solid solubility of point defects in $\mathrm{Si}$ and pushes the temperature of maximum solid solubility above the invariant reaction temperature - a phenomenon known as retrograde solubility $[8,9,26]$.

\subsection{Driving force due to supersaturation}

In a supersaturated solution in this region of retrograde solubility, a reduction in bulk free energy per atom can be achieved by the precipitation of a second phase, restoring the system to equilibrium solute concentration. This precipitation would be in the form of liquid metal impurity$\mathrm{Si}$ according to the equilibrium phase diagram. For such local, retrograde melting to occur, precipitation forming a liquid droplet must take place above the temperature of the invariant reaction in the binary system. The driving force for precipitation, $\Delta f$, can be described in a first approximation by the excess chemical potential associated 
with the supersaturated condition in a regular solution of $M$ in $\mathrm{Si}[27,28]$ :

$\Delta f=\mathrm{k}_{\mathrm{B}} T \ln \frac{c_{\mathrm{M}}}{c_{\mathrm{M}}^{\mathrm{eq}}}$.

where $\Delta f$ is the reduction in free energy per metal atom, $c_{\mathrm{M}}^{\mathrm{eq}}$ is the equilibrium solubility at the system temperature, $c_{\mathrm{M}}$ is the actual dissolved metal concentration, $\mathrm{k}_{\mathrm{B}}$ is the Boltzmann constant and $T$ is the temperature. The maximum possible driving force for retrograde melting in a given binary system arises if the solution is established at the temperature of maximum solubility (e.g. by external contamination) and then cooled to the bounding invariant reaction temperature without precipitation. The maximum possible driving force for precipitation into a liquid droplet is then:

$\Delta f_{\max }=\mathrm{k}_{\mathrm{B}} T_{\text {inv }} \ln \frac{c_{\mathrm{M}}\left(T_{\max }\right)}{c_{\mathrm{M}}\left(T_{i n v}\right)}$.

where $T_{\text {inv }}$ is the invariant reaction temperature and $T_{\max }$ refers to the temperature of maximum solid solubility. The maximum driving force for a number of Si binary systems is tabulated in the Appendix using Eq. (2) and existing experimental data from the literature. From the simple calculation, it is seen that many metal-silicon systems, especially those with low invariant reaction temperatures, are capable of developing driving forces in excess of $100 \mathrm{meV}$ for retrograde melting.

\subsection{Nucleation energy barrier}

For retrograde melting to occur, the nucleation energy barrier must be overcome. Factors that increase the nucleation energy barrier can include charge state (electrostatic repulsion), interface energy and volumetric strain. Generally, the interface and volumetric strain energy terms can be minimized by the presence of lattice defects, including (in order of increasing favorability) certain types of dislocations, grain boundaries and free surfaces [29]. Heterogeneous nucleation of various supersaturated transition metal species in Si is often observed at such lattice defects $[30,31]$, especially under slow (near-equilibrium) cooling conditions. $\mathrm{Ni}$, the metal impurity of interest in this experiment, is known to have a small nucleation energy barrier relative to other transition metals due to nearly coherent precipitation $[22,23]$ and neutral charge state during point defect diffusion [32]. This small nucleation energy barrier makes $\mathrm{Ni}-\mathrm{Si}$ advantageous for this experiment, but in other material systems a significant nucleation energy barrier could completely counteract the driving force, maintaining the system in a metastable state.

\section{Materials and methods}

To investigate retrograde melting in the $\mathrm{Ni}-\mathrm{Si}$ system, we intentionally contaminated $\mathrm{Si}$ samples with Ni concentrations above the peritectic concentration, heated the samples to temperatures above the Ni-Si peritectic $\left(T_{p e r}\right)$, and then cooled slowly to room temperature while monitoring $\mathrm{Ni}$ precipitate distribution and chemical state. The experiment verifies the pathway shown in Fig. 1.

\subsection{Sample preparation}

To reduce the effects of unintentional impurities and defects, a p-type (100) monocrystalline float zone (FZ) Si was used, with a resistivity of $10-200 \Omega \mathrm{cm}$, a single-side polish and a thickness of $675 \mu \mathrm{m}$. Four $10 \times 20 \mathrm{~mm}^{2}$ samples were cut using a $1064 \mathrm{~nm}$ fiber laser and were labeled A, B, C and Reference. The samples were then cleaned using a three-step process: organic solvents, a deionized (DI) water rinse and a $30 \mathrm{~s}$ dip into $10 \%$ hydrofluoric (HF) acid to remove the native oxide layer. Within 30 min following the HF dip, the samples were moved into a vacuum chamber of a Sharon E-beam evaporator to avoid substantial regrowth of the native surface oxide [33]. A $1 \mu \mathrm{m}$ layer of $\mathrm{Ni}$ was evaporated onto the unpolished side of the samples from a high-purity $\mathrm{Ni}$ target. After this step, the Reference sample was set aside. Samples $\mathrm{A}, \mathrm{B}$ and $\mathrm{C}$ were then in-diffused with $\mathrm{Ni}$ from the $\mathrm{Ni}$ coated surface layer by annealing for $30 \mathrm{~min}$ in a reducing ambient $\left(7 \% \mathrm{H}_{2} / 93 \% \mathrm{Ar}\right)$ in a vertically aligned high-temperature furnace, following a procedure similar to that described in Refs. $[32,34]$ wherein the samples are quenched into silicone oil at the end of annealing (estimated $200{ }^{\circ} \mathrm{C} \mathrm{s}^{-1}$ quench rate [28]). An 18” type-R thermocouple monitored the temperature of the furnace at the height of the sample. Thermocouple measurements for our annealing conditions were 1012,1110 and $1229^{\circ} \mathrm{C}$ for samples A, B and $\mathrm{C}$, respectively, corresponding to $\mathrm{Ni}$ concentrations of $1.7 \times 10^{17}, 4.2 \times 10^{17}$ and $6.5 \times 10^{17} \mathrm{~cm}^{-3}$ [9]. The samples were washed thoroughly in DI water and sonicated in acetone to remove the oil. A mixture of $10 \% \mathrm{HCl}$ in water was then used to remove all metals from the surface. Samples were mechanically polished to remove the nickel silicide surface layer and reduce surface heterogeneous nucleation sites, ending with a polish using a $50 \mathrm{~nm}$ alumina suspension. At this point, for each annealing condition, a $5 \times 5 \mathrm{~mm}^{2}$ square was cleaved from the larger $10 \times 20 \mathrm{~mm}^{2}$ sample for synchrotron experiments. Using a diamond scribe, a single scratch was intentionally introduced on the polished surface of these samples to provide a known, favorable heterogeneous nucleation site for $\mathrm{Ni}$ accumulation during in situ measurement.

\subsection{In situ synchrotron microprobe measurements}

Hard X-ray microprobe measurements on the $\mathrm{Ni}-\mathrm{Si}$ samples were carried out at beamline 10.3.2 of the Advanced Light Source at Lawrence Berkeley National Laboratory, Berkeley, CA [35]. To determine the chemical state and distribution of $\mathrm{Ni}$ at elevated temperatures, a modified Linkam TS-1500 hot stage was employed as previously described in Ref. [6]. The stage uses a $10 \mu \mathrm{m} \mathrm{Si}$ window to allow X-ray transparency while maintaining a 
neutral (non-oxidizing) nitrogen ambient atmosphere during annealing. X-ray fluorescence (XRF) elemental maps of large areas (up to square millimeters) were collected with spatial resolution down to $\approx 2 \times 2 \mu \mathrm{m}^{2}$ and high sensitivity $\left(>10^{14} \mathrm{~cm}^{-2} \mathrm{~s}^{-1}\right)$ [36]. Ni K-edge micro X-ray absorption spectroscopy ( $\mu$-XAS) was performed on Ni-concentrated areas to determine the chemical state. All XAS measurements were performed in fluorescence mode using quick scanning XAS (QXAS), by slewing the Si (1 111$)$ monochromator continuously from low to high energies as the X-ray absorption data are acquired with a seven-element germanium detector (Canberra, ON). QXAS allowed 176 data points around the $\mathrm{NiK} \alpha$ absorption edge (a single scan between 8233 and $8462 \mathrm{eV}$ ) to be acquired in approximately $20 \mathrm{~s}$ with $0.1 \mathrm{eV}$ repeatability, enabling high effective counts before metals out-diffused from the sample.

Once mounted in the hot stage, the Reference sample, with its $1 \mu \mathrm{m}$ layer of $\mathrm{Ni}$ intact on the $\mathrm{Si}$ surface, was heated at $100{ }^{\circ} \mathrm{C} \mathrm{min}^{-1}$ to above $1100{ }^{\circ} \mathrm{C}$, whereupon high-temperature QXAS measurements were taken to confirm its liquid phase. The sample was then cooled in 10 $20{ }^{\circ} \mathrm{C}$ steps at a rate of $100{ }^{\circ} \mathrm{C} \mathrm{min}{ }^{-1}$. $\mu$-XRF mapping was initiated after a $1 \mathrm{~min}$ stabilization time at each temperature, allowing equilibration and diffusion of $\mathrm{Ni}$ to available nucleation sites. With the exception of a few large overview maps, measurements on all samples were performed as follows: each $\mu$-XRF map, recorded at $8481 \mathrm{eV}$, lasted roughly $1.5 \mathrm{~min}$, using $10 \times 10 \mu \mathrm{m}^{2}$ pixel size and a $50 \mathrm{~ms}$ dwell time per pixel. Once a Ni particle was located, 20 QXAS scans were obtained in rapid succession for noise averaging. Following QXAS measurements, the temperature was decreased by $10-20^{\circ} \mathrm{C}$ and the cycle repeated until well below the observation of solidification. Samples A, B and C were heated at $100{ }^{\circ} \mathrm{C} \mathrm{min}^{-1}$ to a temperature above the corresponding furnace in-diffusion temperature to dissolve all precipitates formed during the quench. After confirming with $\mu$-XRF that complete $\mathrm{Ni}$ precipitate dissolution occurred, the samples were cooled in $10-20{ }^{\circ} \mathrm{C}$ steps until precipitation was observed, and the chemical state of $\mathrm{Ni}$ was then monitored by QXAS at each temperature as described above,

XAS spectra were deadtime corrected, deglitched and calibrated using LabVIEW (National Instruments) custom programs available at the beamline. Spectra were calibrated using the inflection point of elemental $\mathrm{Ni}$ at $8331.49 \mathrm{eV}$ [37]. Spectra were then pre-edge background subtracted and post-edge normalized using standard procedures with the Athena software [38]. Least-squares linear combination fitting was also performed with the Athena software.

\section{Results}

\subsection{Reference sample}

$\mu$-XRF maps of the Reference sample were acquired throughout the heating to locate $\mathrm{Ni}-\mathrm{Si}$ precipitates where

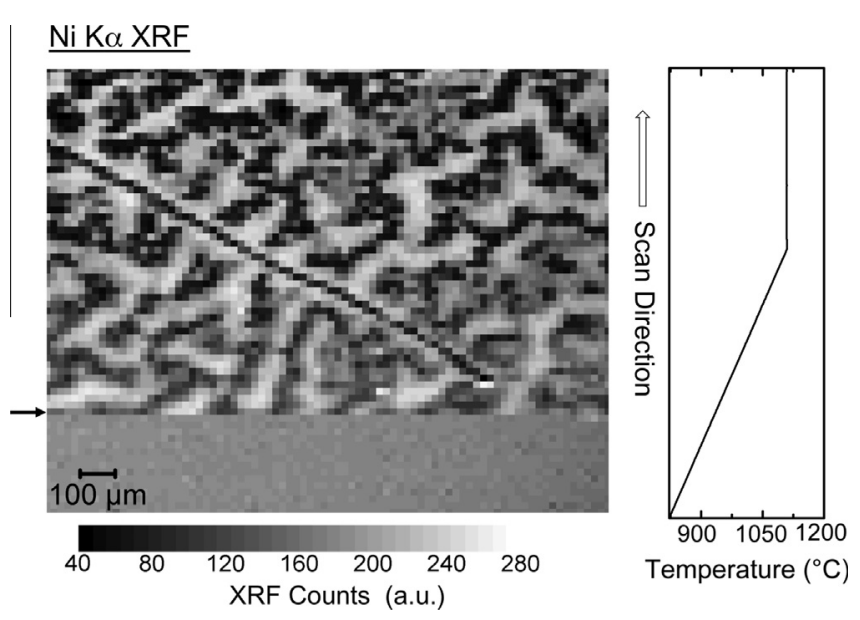

Fig. 2. Ni distribution map of the Reference sample during heating. The map was completed from bottom to top while heating, and the corresponding sample temperature is shown to the right. At approximately $1000^{\circ} \mathrm{C}$, the $1 \mu \mathrm{m}$ Ni film visibly dewets (as marked by the arrow to the left of the map), indicating the onset of melting.

reference XAS spectra for high-temperature liquid $\mathrm{Ni}-\mathrm{Si}$ and solid $\mathrm{NiSi}_{2}$ phases could be obtained. Initially, a homogeneous $\mathrm{Ni}$ distribution was observed, then an abrupt change occurred at roughly $1000^{\circ} \mathrm{C}$, as the uniform film evolved into concentrated Ni islands (Fig. 2). This visible dewetting of the Ni surface film provided the first experimental confirmation of the phase transition to a liquid state in our samples. Note that this melting occurs homogeneously during heating and so is not retrograde in character, but was used to establish reference spectra for fingerprinting the high-temperature liquid state (see Fig. 2).

To establish the differential determination of liquid phase spectra, QXAS spectra were acquired as the sample was cooled as described in Section 3.2. As seen in energyspace in Fig. 3a, an abrupt change in the $\mathrm{Ni}$ absorption spectrum is observed during cooling, indicative of the solidification phase transition. The spectra themselves are qualitatively consistent with previous Ni $\mu$-XAS measurements of liquid Ni-Si and solid $\mathrm{NiSi}_{2}$ phases [6]. The spectrum at $887^{\circ} \mathrm{C}$ suggests a transition between the high-temperature liquid Ni-Si spectra and lower-temperature fully solidified $\mathrm{NiSi}_{2}$. Least-squares linear combination fitting of the $887^{\circ} \mathrm{C}$ spectrum using spectra at lowest $\left(848^{\circ} \mathrm{C}\right)$ and highest $\left(1108^{\circ} \mathrm{C}\right)$ temperatures results in weights of 0.55 and 0.45 , respectively. To provide further insight into the local structure around the $\mathrm{Ni}$ atoms, the data were converted from energy-space into momentum (k)-space (Fig. 3b). As evidenced by their reduced scattering oscillation structure, the liquid $\mathrm{Ni}-\mathrm{Si}$ spectra show a greater degree of disorder than the solid $\mathrm{NiSi}_{2}$ as expected in a liquid absorption spectra. The relative order in the k-space spectrum at $887^{\circ} \mathrm{C}$ further supports a transition to solid $\mathrm{NiSi}_{2}$ at $887^{\circ} \mathrm{C}$, over $100^{\circ} \mathrm{C}$ below the temperature of observed melting (Fig. 3). Further heating and cooling of the sample confirmed that this hysteresis was repeatable. Discussion of the possible origin of the hysteresis is presented in Section 5. 

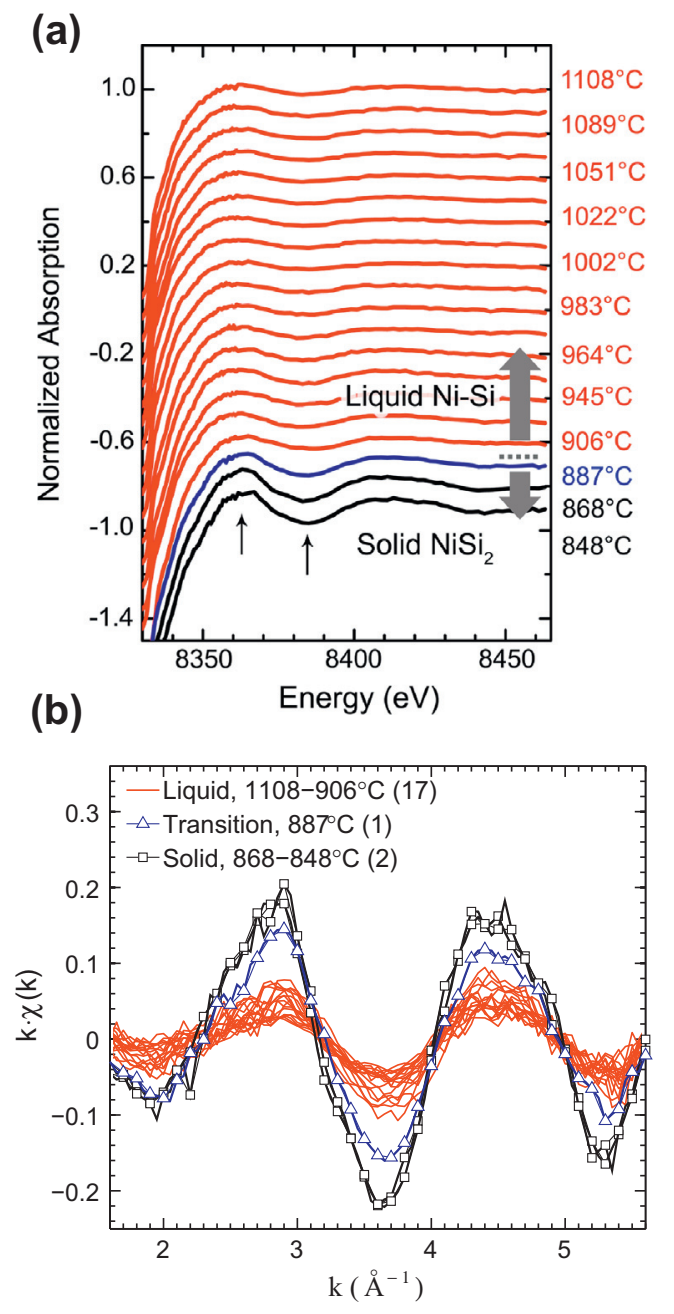

Fig. 3. (a) Normalized X-ray absorption spectra of Ni-rich precipitates in the Reference sample for a range of temperatures during cooling of the sample. Spectra were shifted vertically for clarity. At high temperatures, the spectra (in red) indicate a liquid $\mathrm{Ni}-\mathrm{Si}$ phase with little structure beyond the absorption edge. At $887^{\circ} \mathrm{C}$, the spectrum (in blue) revealed significant differences in structure, showing oscillations (indicated by arrows at $\approx 8365$ and $8385 \mathrm{eV}$ ) indicating the onset of solidification. Further cooling intensified the EXAFS oscillations (black). (b) Spectra from (a) converted into k-space. The legend includes the temperature range during cooling where the phase was observed in the sample and, in parentheses, the number of spectra measured in that temperature range. The k-weighted $\chi(k)$ XAS signal shows a clear transition from liquid to solid depending on the temperature. (For interpretation of the references to color in this figure legend, the reader is referred to the web version of this article.)

\subsection{Annealed samples}

$\mathrm{NiSi}_{2}$ is closely lattice-matched to $\mathrm{Si}$, with less than a $0.4 \%$ mismatch [23]. The need for only a small volume change leads to extensive $\mathrm{Ni}$ precipitation within the bulk during quenching. Accordingly, small, localized particles containing $\mathrm{Ni}$ can be observed as single-pixel hotspots in the room-temperature map of sample B (Fig. 4a), taken after the quench but prior to in situ annealing. During sample heating, additional nucleation at the intentionally intro-

\section{$\mathrm{Ni} \mathrm{K \alpha}$ XRF}

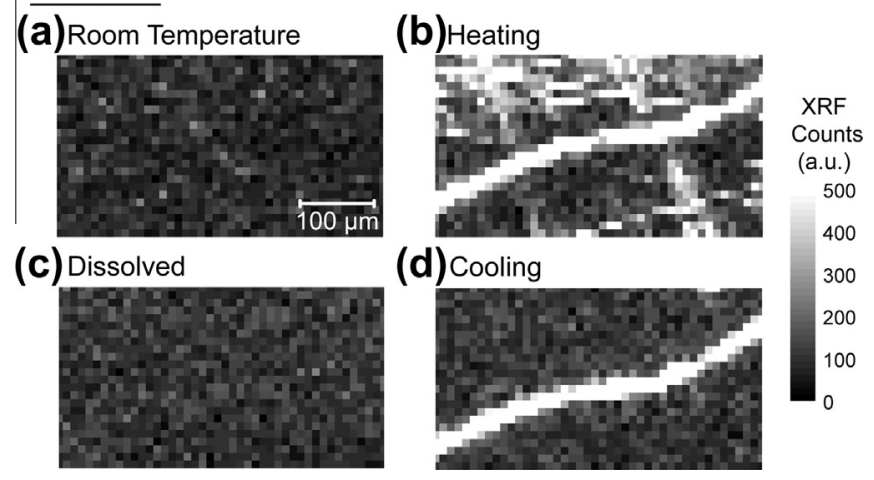

Fig. 4. Representative Ni $\mu$-XRF maps of the same region of sample B taken at different stages of in situ measurement. (a) At room temperature, following the quench, and prior to any further annealing. Single-pixel hotspots indicate the presence of small precipitates formed during the quench. (b) During heating to the in-diffusion temperature. Large Ni concentrations are observed at available defect sites in addition to the intentionally introduced scratch as the elevated diffusivity allows ripening to occur. (c) At a temperature above the in-diffusion annealing temperature such that the $\mathrm{Ni}$ has dissolved and is only present as a low, diffuse background level. (d) Upon slow cooling from this dissolved state, $\mathrm{Ni}$ reprecipitates only at the most favorable nucleation site, the intentionally introduced surface defect. All subsequent QXAS measurements were taken on precipitates along the scratch. The scale bar applies to all maps.

duced scratch and some Ostwald ripening was observed (Fig. 4b). Ni appears to aggregate at both bulk and surface defects as evidenced by the map of the same region using the same intensity scale. Once the temperature of the contamination anneal was surpassed, the $\mathrm{Ni}$ solid solubility exceeded the total concentration in the wafer, and all particles dissolved as seen in Fig. 4c. After all the Ni returned to the dissolved state, the sample was cooled, forcing $\mathrm{Ni}$ supersaturation and precipitation. The relatively slow cool during in situ annealing allowed metals to diffuse to, and aggregate at, the most energetically favorable heterogreneous nucleation site, an intentional scratch on the sample surface, per Fig. 4d.

As the sample cooled, QXAS spectra were collected between $\mu$-XRF maps, as described in Section 3.2. Resulting spectra for each sample are shown in Fig. 5 in k-space to track more easily the chemical changes. All sample spectra show a sharp increase in structure and amplitude of EXAFS oscillations upon reaching solidification temperatures. Each QXAS spectrum, recorded at a specific temperature, was classified as either liquid $\mathrm{Ni}-\mathrm{Si}$ or solid $\mathrm{NiSi}_{2}$ by comparison with spectra of standards obtained from the Reference sample (Fig. 3b). Subsequently, to determine the weights of the liquid and solid phases as a function of temperature, least-squares linear combination fitting (LCF) of each sample spectrum was performed in the energy range from $20 \mathrm{eV}$ below to $120 \mathrm{eV}$ above the edge. Due to damped EXAFS oscillations in the standards obtained from the Reference sample with respect to the annealed sample spectra, the highest- $\left(1204^{\circ} \mathrm{C}\right)$ and lowest- $\left(819^{\circ} \mathrm{C}\right)$ temperature spectra from the annealed sam- 
(a)

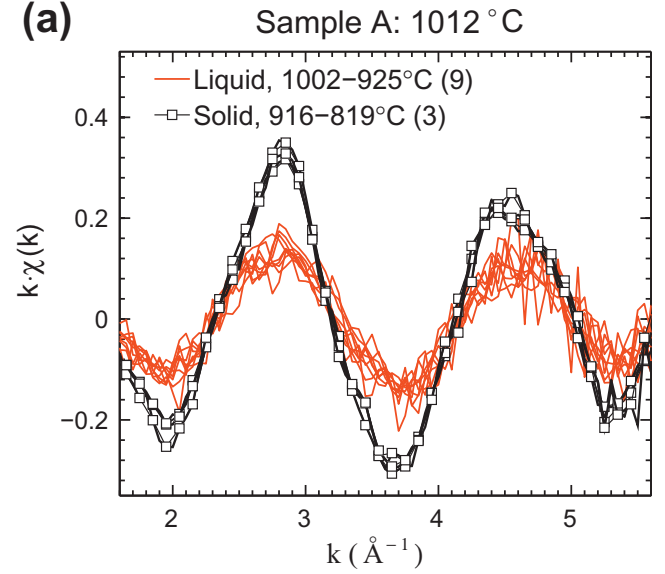

(b)

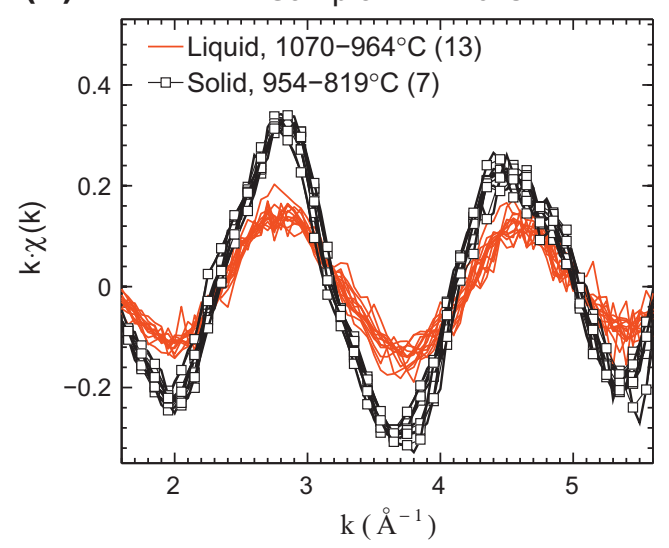

(c)

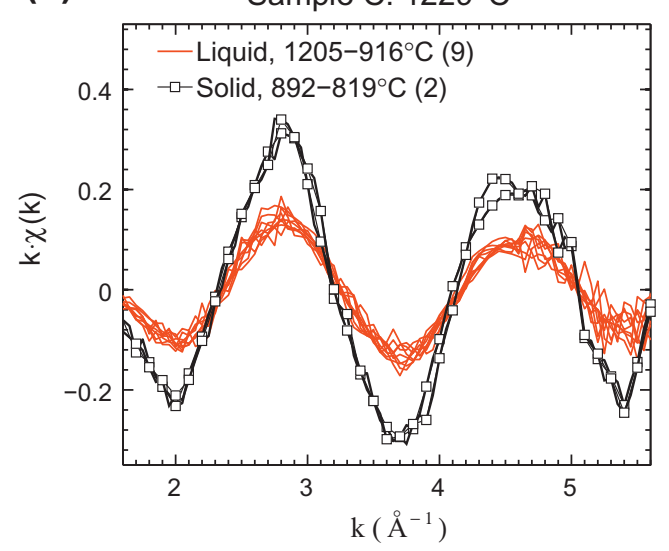

Fig. 5. k-weighted XAS spectra of annealed samples (a) sample A, (b) sample B and (c) sample C, at various temperatures. Spectra are fingerprinted as liquid (red) or solid (black) by comparison to spectra of standards obtained from the Reference sample and displayed in Fig. $2 b$. All samples exhibit a sharp transition from liquid precipitates to solid. The legend includes the temperature range during cooling where the phase was observed in the sample and, in parentheses, the number of spectra measured in that temperature range. (For interpretation of the references to color in this figure legend, the reader is referred to the web version of this article.)

ples were used instead as standards for LCF. This oscillation damping is most likely due to overabsorption in the thick Ni layer of the Reference sample. The fitted weights

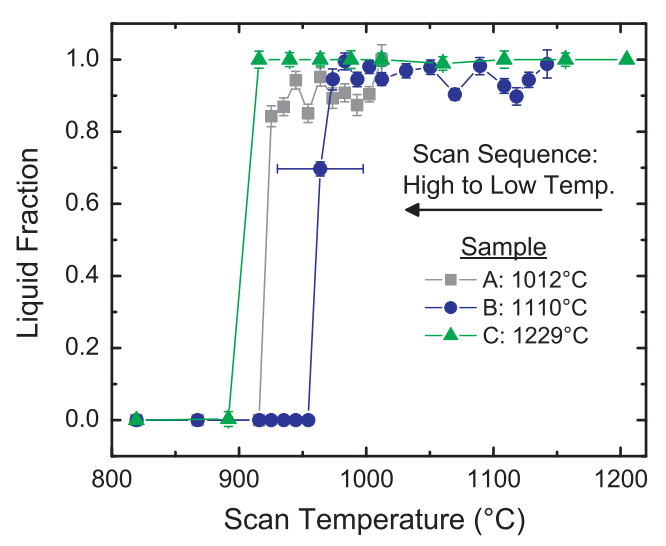

Fig. 6. Least-squares linear combination fitting results for each sample spectrum reveals the fraction of the spectrum that can be attributed to the liquid, high-temperature state. A sharp solidification transition occurs in each sample. LCF error bars represent one standard deviation on the fit, assuming all points in the XAS spectra are independent and all noise is statistical in nature. The temperature error bar shown for the $1110^{\circ} \mathrm{C}$ sample is representative of the maximum uncertainty for all temperatures.

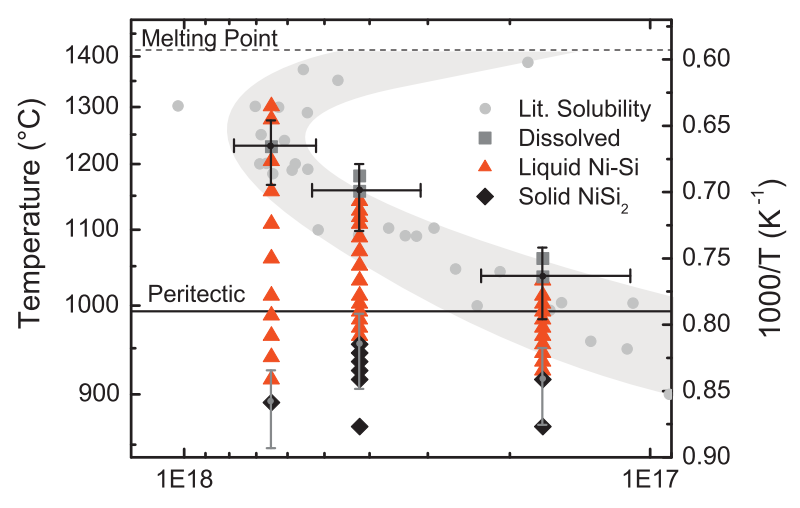

Ni Concentration $\left(\mathrm{cm}^{-3}\right)$

Fig. 7. Aggregated chemical state data as a function of temperature for each sample overlaid on existing $\mathrm{Ni}$ solubility data from the literature [32,39-41]. The peritectic temperature (solid line) and Si melting temperature (dashed line) are shown for reference. Three states of Ni can be observed: completely dissolved (square), liquid $\mathrm{Ni}-\mathrm{Si}$ (triangle) and solid $\mathrm{NiSi}_{2}$ (diamond). Error bars in temperature show the maximum uncertainty expected in the temperature measurement. Error bars are included for both the measured dissolution temperature and the solidification temperature to assist the eye because of the nonlinear temperature scale of the figure. Concentration error bars reflect a $2 \%$ uncertainty in the indiffusion temperature.

for the high-temperature, liquid state are plotted in Fig. 6 for each spectrum. LCF suggests that each sample moves from a high-temperature state abruptly to a low-temperature solidified state, supporting the fingerprinting of the spectra between the two phases.

\subsection{Model confirmation and discrepancies}

Fig. 7 shows the chemical state for each sample as measured by QXAS superimposed on a phase diagram, following the early example of Ref. [42] on the use of XAS to map 
effective phase boundaries. In addition to the spectra shown for samples A, B and C in Fig. 5, several highertemperature data points are included in Fig. 7 where the $\mu$-XRF map showed precipitation. Their corresponding QXAS spectra were roughly fingerprinted but were too noisy for LCF, most likely due to increased thermal vibrations and the Debye-Waller effect, and not included in Fig. 5. Literature solubility data are included in the figure $[39,32,40,41]$ to indicate the uncertainty in the solvus line. The sample data are located along the abscissa according to the $\mathrm{Ni}$ concentration corresponding to their in-diffusion anneal temperature (from [9]). These presumed Ni concentrations are consistent within the variation of the literature data, and inductively-coupled plasma mass spectrometry measurements of the non-in situ annealed portion of each sample agree with the indicated $\mathrm{Ni}$ concentrations. Furthermore, the relative concentrations between the samples according to their in-diffusion temperature are also consistent with the relative $\mathrm{Ni}$ counts measured in the highesttemperature $\mu$-XRF maps where all Ni was completely dissolved. Temperatures were calibrated by ex situ optical pyrometry. All ex situ measurements fell within a $4 \%$ temperature deviation from the calibration. Error bars provided for each sample at the observed solidification temperature indicate this $4 \%$ maximum deviation. Concentration error bars are estimated from the available literature solubility data given the $2 \%$ uncertainty in indiffusion temperature for each sample.

\section{Discussion}

Direct experimental evidence of the retrograde solubility of $\mathrm{Ni}$ in $\mathrm{Si}$ is provided by the in situ measurements of sample $\mathrm{C}$. In the model of retrograde solubility, there exists a maximum solubility point in the $\mathrm{Ni}-\mathrm{Si}$ system above the peritectic temperature, with decreased solubility above and below this temperature. For sample C, during heating of the sample, dissolution of quenched-in precipitates was observed as we passed the temperature of initial contamination. Upon further heating, reprecipitation was observed and QXAS measurement determined the precipitates to be in the liquid $\mathrm{Ni}-\mathrm{Si}$ state, confirming the retrograde nature of $\mathrm{Ni}$ solubility in $\mathrm{Si}$ and suggesting that sample $\mathrm{C}$ was contaminated close to maximum solubility for $\mathrm{Ni}$ in $\mathrm{Si}$.

In all samples, the QXAS analyses collected in Fig. 7 reveal retrograde melting driven by this retrograde character of Ni solubility. Ni precipitates directly to a liquid $\mathrm{Ni}-\mathrm{Si}$ state upon cooling from the high-temperature dissolved state, with little or no undercooling appeared to be required for the precipitation to occur. Liquid precipitation is observed to commence upon cooling below the contamination temperature, evidenced by the transition from dissolved $\mathrm{Ni}$ (squares) to liquid Ni-Si (triangles) just below the contamination temperature as shown in Fig. 7. The chemical state data follow the solvus quite closely for the initial precipitation of second-phase liquid Ni-Si. Further, upon temperature cycling, the formation and dissolution of these liquid second-phase particles occur near the contamination temperature with no hysteresis and in agreement with theoretical predictions in a system with a variety of heterogenous nucleation sites (such as those provided by the surface scratches) This immediate retrograde melting at mechanically induced surface defects is in good agreement with previous results where high Si surface energy, even without supersaturation, drove liquid nickel silicide to form at surface scratches on the front side of an Si wafer during annealing above the peritectic temperature with a Ni source on the backside [24]. To summarize, in a system exhibiting retrograde solubility where heterogeneous nucleation sites are available, retrograde melting can be expected to occur upon any significant local supersaturation during cooling.

On the other hand, there appears to be a difference for all samples in the experimentally measured solidification temperature of the liquid droplets and the established peritectic temperature of the binary system, indicating an energy barrier to solidification for these microscopic liquid droplets. Undercooling below the peritectic temperature is required to transition from liquid $\mathrm{Ni}-\mathrm{Si}$ (triangles) to a solid $\mathrm{NiSi}_{2}$ phase (diamonds), as seen in Fig. 7. In addition, a hysteresis in the liquid-to-solid phase transition temperature was observed during Reference sample heating and cooling. A non-negligible energy barrier for the formation of solid $\mathrm{NiSi}_{2}$ precipitates could explain these two observations. Though the experiments here were not targeted at determining the contributions to this energy barrier, similar hystereses have been observed in other systems involving liquid droplets on or in a solid matrix and were attributed to interface effects $[43,44]$.

In addition, in the particular case of $\mathrm{NiSi}_{2}$ precipitation, it has been established by quenching samples from $1050{ }^{\circ} \mathrm{C}$ (500-1000 ${ }^{\circ} \mathrm{C} \mathrm{s}^{-1}$ ) that $\mathrm{NiSi}_{2}$ precipitation during quenching begins with the formation of two $\{111\}$ layers with interfaces constructed of $\mathrm{Si}-\mathrm{Si}$ bonds, demanding a geometrically required bounding dislocation [45]. The large interfaces of these platelets and the requirement of the generation of the bounding dislocation are highly energetically unfavorable, but the $\mathrm{NiSi}_{2}$ platelets are understood to form in this way due to kinetic favorability as $\mathrm{Ni}$ interstitials can be incorporated rapidly at the dislocation core [23]. In the experiments presented here, the samples are not quenched but instead are cooled more slowly. The slower cooling perhaps allows some incorporation of supersaturated Ni interstitials into the metastable liquid droplets, reducing the magnitude of the driving force that might lead to relatively energetically expensive $\mathrm{NiSi}_{2}$ platelet formation. Instead, $\mathrm{NiSi}_{2}$ precipitates may eventually form in more energetically favorable configurations, such as those observed in [22], that result from kinetically slower processes. Thus, it is possible that the undercooling observed to be required for solidification in the in situ experiments here reflects the tradeoff between energetically and kinetically favored precipitation pathways for $\mathrm{NiSi}_{2}$ formation. Further investigations are necessary. 


\subsection{Extension of the framework to multinary systems}

Most solutes in Si exhibit some departure from ideality $[9,46]$ and non-idealities worsen with additional, interacting solute species. The extension of the thermodynamic framework of retrograde melting to systems with multiple impurities hinges on the evolution of $c_{\mathrm{M}}\left(T_{\text {max }}\right)$ and $c_{\mathrm{M}}\left(T_{\text {inv }}\right)$ with the addition of other elements. Computational comparisons of $c_{\mathrm{M}}\left(T_{\max }\right)$ in multinary and binary systems have been performed $[47,48]$, suggesting only a minor influence of other elements over the maximum solid solubility of one given element. On the other hand, the term $c_{\mathrm{M}}\left(T_{i n v}\right)$ is expected to be significantly reduced by the presence of other elements. Differential scanning calorimetry experiments suggest that liquid phases can be present in multinary $\mathrm{Cu}-\mathrm{Fe}-\mathrm{Ni}-\mathrm{Si}$ systems at temperatures as low as $740{ }^{\circ} \mathrm{C}[11]$, significantly below the lowest binary eutectic temperature of any two elements in the multinary system (i.e. $\mathrm{Cu}-\mathrm{Si}$ at $802{ }^{\circ} \mathrm{C}$ ). These data suggest retrograde melting may be more favorable in certain multinary systems than pure binary systems. Indeed, retrograde melting has already been observed in multinary $\mathrm{Ni}-\mathrm{Fe}-\mathrm{Cu}-\mathrm{Si}$ systems [6]. A more detailed calculation of the driving force should be possible with a more thorough thermodynamic dataset and available computational tools [47], but the simplicity of Eq. (2) provides insight into the retrograde melting mechanism.

\section{Conclusions}

Local, retrograde melting is observed directly in the $\mathrm{Ni}-$ Si system using synchrotron-based in situ X-ray microprobe techniques. X-ray absorption spectroscopy is used to identify the liquid nature of $\mathrm{Ni}-\mathrm{Si}$ precipitates upon cooling from solid solution and to determine the evolution of their chemical state as a function of temperature. The experimental observations largely match thermodynamic predictions, confirming the local melting model presented here for the case of $\mathrm{Ni}-\mathrm{Si}$. Generalizing from these observations, retrograde melting is expected to occur where heterogeneous nucleation sites are available in systems exhibiting retrograde solubility. Second-phase liquid precipitates form upon supersaturation, but the temperature at which the liquid-droplet precipitates solidify is suppressed below the system peritectic, perhaps due to the development of higher interfacial energy and volumetric strain during solidification. In multinary systems in which suppression of the eutectic temperature occurs, retrograde melting may be even more favorable. This framework enables more accurate modeling and predictive control of high-temperature impurity behavior in metal-silicon systems such as cost-effective silicon feedstock and solar cell materials.

\section{Acknowledgements}

We thank J. McGinn and S. Cortes at McCrone Scientific for their equipment support; M. Heuer, S. Langkau, M.D. Pickett, S. Riepe for enlightening discussions; and Y.S. Lee for assisting with e-beam evaporation. Support for this research was provided by the US Department of Energy, under Contract No. DE-FG36-09GO19001, and through the generous support of Doug Spreng and the Chesonis Family Foundation. D.P.F. and S.H. acknowledge National Science Foundation Graduate Research Fellowships; B.K.N. the Claire Boothe Luce Foundation. The Advanced Light Source is supported by the Director, Office of Science, Office of Basic Energy Sciences, of the US

Table A1

The driving force for local retrograde melting (Eq. (2)) is tabulated for elements that are known empirically to exhibit retrograde solubility in Si.

\begin{tabular}{|c|c|c|c|c|c|}
\hline Solute & Invariant temp. $(\mathrm{K})$ & $c\left(T_{i n v}\right)\left(\mathrm{cm}^{-3}\right)$ & $c\left(T_{\max }\right)\left(\mathrm{cm}^{-3}\right)$ & $\Delta f_{\max }\left(\mathrm{meV}\right.$ atom $\left.^{-1}\right)$ & Ref. \\
\hline $\mathrm{Li}$ & 865 & $4.5 \times 10^{18}$ & $6.0 \times 10^{19}$ & 193 & {$[47,49]$} \\
\hline $\mathrm{Mg}$ & 1218.6 & $5.0 \times 10^{18}$ & $1.5 \times 10^{19}$ & 115 & {$[47,50]$} \\
\hline $\mathrm{Al}$ & 850 & $9.0 \times 10^{17}$ & $2.0 \times 10^{19}$ & 227 & {$[47,49]$} \\
\hline $\mathrm{S}$ & 1475 & $1.7 \times 10^{16}$ & $3.1 \times 10^{16}$ & 76 & {$[25,49]$} \\
\hline $\mathrm{Ca}$ & 1303 & $2.4 \times 10^{18}$ & $6.0 \times 10^{18}$ & 103 & {$[50]$} \\
\hline $\mathrm{Mn}$ & 1422 & $9.5 \times 10^{15}$ & $3.5 \times 10^{16}$ & 160 & {$[46]$} \\
\hline $\mathrm{Fe}$ & 1480 & $1.6 \times 10^{16}$ & $2.2 \times 10^{16}$ & 41 & [9] \\
\hline $\mathrm{Co}$ & 1532 & $2.8 \times 10^{16}$ & $3.1 \times 10^{16}$ & 13 & [9] \\
\hline $\mathrm{Ni}$ & 1266 & $2.2 \times 10^{17}$ & $7.0 \times 10^{17}$ & 126 & [9] \\
\hline $\mathrm{Cu}$ & 1075 & $6.0 \times 10^{16}$ & $1.6 \times 10^{18}$ & 304 & [9] \\
\hline $\mathrm{Zn}$ & 693 & $1.3 \times 10^{6 *}$ & $8.0 \times 10^{16}$ & 1480 & {$[46]$} \\
\hline $\mathrm{Ga}$ & 302.8 & $1.1 \times 10^{16^{*}}$ & $3.0 \times 10^{19}$ & 206 & {$[46,49]$} \\
\hline $\mathrm{Pd}$ & 1165 & $3.0 \times 10^{16}$ & $2.8 \times 10^{17}$ & 224 & [51] \\
\hline $\mathrm{Ag}$ & 1108 & $1.8 \times 10^{6^{*}}$ & $6.5 \times 10^{16}$ & 2320 & {$[46]$} \\
\hline In & 429.6 & $2.1 \times 10^{8 *}$ & $2.0 \times 10^{18}$ & 851 & {$[46]$} \\
\hline $\mathrm{Sn}$ & 505 & $7.0 \times 10^{17 *}$ & $7.5 \times 10^{19}$ & 203 & {$[46]$} \\
\hline $\mathrm{Sb}$ & 903 & $2.0 \times 10^{19}$ & $5.0 \times 10^{19}$ & 197 & {$[46,49]$} \\
\hline $\mathrm{Pt}$ & 1243 & $5.9 \times 10^{15}$ & $1.2 \times 10^{17}$ & 323 & {$[52]$} \\
\hline $\mathrm{Au}$ & 636 & $8.6 \times 10^{7 *}$ & $1.0 \times 10^{17}$ & 1140 & {$[53,46]$} \\
\hline $\mathrm{Bi}$ & 544 & $1.0 \times 10^{6 *}$ & $1.0 \times 10^{18}$ & 1300 & [46] \\
\hline
\end{tabular}

\footnotetext{
* Extrapolated from available experimental data to lower temperatures.
} 
Table A2

Elements that have an invariant reaction on the Si-rich side but are believed to exhibit no retrograde solubility in $\mathrm{Si}$.

\begin{tabular}{lll}
\hline Solute & Invariant temp. (K) & Ref. \\
\hline $\mathrm{B}$ & 1658 & {$[25]$} \\
$\mathrm{Sc}$ & 1538 & {$[25]$} \\
$\mathrm{Ti}$ & 1603 & {$[46]$} \\
$\mathrm{V}$ & 1673 & {$[47]$} \\
$\mathrm{Cr}$ & 1608 & {$[46]$} \\
$\mathrm{As}$ & 1370 & {$[25]$} \\
$\mathrm{Zr}$ & 1643 & {$[47]$} \\
$\mathrm{Mo}$ & 1673 & {$[47]$} \\
$\mathrm{W}$ & 1663 & {$[47]$} \\
$\mathrm{U}$ & 1588 & {$[25]$} \\
\hline
\end{tabular}

Department of Energy under Contract No. DE-AC0205CH11231. Sample cleaning and evaporation was performed at the Harvard Center for Nanoscale Systems (CNS), supported by the National Science Foundation under award No. ECS-0335765.

\section{Appendix A}

See Tables A1 and A2.

\section{References}

[1] Cahill DG, Ford WK, Goodson KE, Mahan GD, Majumdar A, Maris HJ, et al. J Appl Phys 2003;93(2):793-818.

[2] Graff K. New York: Springer; 2000.

[3] Queisser HJ, Haller EE. Science 1998;281(5379):945-50.

[4] Berry AJ, Hack AC, Mavrogenes JA, Newville M, Sutton SR. Am Mineral 2006;91(11-12):1773-82. http://dx.doi.org/10.2138/am. 2006.1940.

[5] Eeckhout SG, Gorges B, Barthe L, Pelosi O, Safonova O, Giuli G. J Synchrotron Radiat 2008;15(5):489-94.

[6] Hudelson S, Newman BK, Bernardis S, Fenning DP, Bertoni MI, Marcus MA, et al. Adv Mater 2010;22(35):3948-53.

[7] Abrikosov NK, Poretskaya LV. Izv Akad Nauk SSSR Neorgan Materialy 1965;1(4):503-10.

[8] Thurmond CD, Struthers JD. J Phys Chem 1953;57(8):831-5.

[9] Weber ER. Appl Phys A: Mater Sci Process 1983;30:1-22.

[10] Ganapati V, Fenning DP, Bertoni MI, Kendrick CE, Fecych AE, Redwing JM, et al. Small 2011;7(5):563-7.

[11] Heuer M, Buonassisi T, Istratov AA, Pickett MD, Marcus MA, Minor AM, et al. J Appl Phys 2007;101(12):123510.

[12] Buonassisi T, Heuer M, Istratov A, Pickett M, Marcus M, Lai B, et al. Acta Mater 2007;55(18):6119-26.

[13] Nordmark H, Di Sabatino M, Acciarri M, Libal J, Binetti S, Øvrelid EJ, et al. In: 33rd IEEE Photovoltaic Specialists Conference (PVSC); 2008. p. 1-6.

[14] Zuschlag A, Ohl S, Bernhard J, Morhenn H, Ebser J, Junge J, et al. In: 2010 35th IEEE Photovoltaic Specialists Conference (PVSC); 2010. p. 347-51.

[15] Riepe S, Reis IE, Kwapil W, Falkenberg MA, Schön J, Behnken H et al. Phys Status Solidi (c) 2011;8(3):733-8.
[16] Naerland TU, Arnberg L, Holt A. Progr Photovoltaics Res Appl 2009;17(5):289-96.

[17] von Känel H. Mater Sci Rep 1992;8:193-269.

[18] Werner P, Mattheis R, Hesse D, Hillebrand R, Heydenreich J. Phys Status Solidi (a) 1989;116(1):81-90.

[19] Ryoo K, Drosd R, Wood W. J Appl Phys 1988;63(9):4440-3.

[20] Portier X, Rizk R. Phys Status Solidi (a) 1996;155(1):125-40.

[21] Istratov AA, Weber ER. Appl Phys A: Mater Sci Process 1998;66(2):123-36.

[22] Langkau S, Wagner G, Kloess G, Heuer M. Phys Status Solidi (a) 2010;207(8):1832-44.

[23] Seibt M, Hedemann H, Istratov AA, Riedel F, Sattler A, Schröter W. Phys Status Solidi (a) 1999;171(1):301-10.

[24] Li J, Yang WS, Tan TY, Chevacharoenkul S, Chapman R. J Appl Phys 1992;71(1):196-203.

[25] Okamoto H. Materials Park, OH: ASM International; 2000.

[26] Fistul VI. New York: CRC Press; 2004.

[27] Schröter W, Seibt M, Gilles D. In: Jackson KA, Schröter W, editors. Handbook of semiconductor technology. John Wiley \& Sons; 2000. p. 597-660.

[28] Istratov AA, Hedemann H, Seibt M, Vyvenko OF, Schroter W, Heiser T, et al. J Electrochem Soc 1998;145(11):3889-98.

[29] Myers SM, Seibt M, Schroter W. J Appl Phys 2000;88(7):3795-819.

[30] Sopori B. J Electron Mater 2002;31:972-80.

[31] Buonassisi T, Istratov AA, Heuer M, Marcus MA, Jonczyk R, Isenberg J, et al. J Appl Phys 2005;97(7):074901.

[32] Istratov AA, Zhang P, McDonald RJ, Smith AR, Seacrist M, Moreland J, et al. J Appl Phys 2005;97(2):023505.

[33] Morita M, Ohmi T, Hasegawa E, Kawakami M, Suma K. Appl Phys Lett 1989;55(6):562-4.

[34] Istratov AA, Huber W, Weber ER. Appl Phys Let 2004;85(19):4472-4.

[35] Marcus MA, MacDowell AA, Celestre R, Manceau A, Miller T, Padmore HA, et al. J Synchrotron Radiat 2004;11(3):239-47.

[36] Buonassisi T, Istratov AA, Marcus MA, Heuer M, Pickett MD, Lai B, et al. Solid State Phenom 2005;108-109:577-84.

[37] Kraft S, Stumpel J, Becker P, Kuetgens U. Rev Sci Instrum 1996;67(3):681-7.

[38] Ravel B, Newville M. J Synchrotron Radiat 2005;12(4):537-41.

[39] Aalberts JH, Verheijke ML. Appl Phys Lett 1962;1(1):19-20.

[40] Wiehl N, Herpers U, Weber E. J Radioanal Nucl Chem 1982; 72(1-2):69-78.

[41] Yoshida M, Furusho K. Jpn J Appl Phys 1964;3(9):521-9.

[42] Marcus MA, Bower JE. J Appl Phys 1997;82:3821-7.

[43] Filipponi A, Borowski M, Loeffen PW, Panfilis SD, Cicco AD, Sperandini F, et al. J Phys Condens Matter 1998;10(1):235-53.

[44] Devaud G, Turnbull D. Acta Metall 1987;35(3):765-9.

[45] Seibt M, Schröter W. Philos Mag A 1989;59(2):337-52.

[46] Yoshikawa T, Morita K, Kawanishi S, Tanaka T. J Alloys Compd 2010;490(1-2):31-41.

[47] Tang K, Øvrelid EJ, Tranell G, Tangstad M. Mater Trans 2009;50(8):1978-84.

[48] Tang K, Øvrelid EJ, Tranell G, Tangstad M. Crystal Growth Si Solar Cells 2009; 14:219-51.

[49] Trumbore FA. Bell Syst Tech J 1960;39:205-33.

[50] Sigmund H. J Electrochem Soc 1982;129(12):2809-12.

[51] Frank, W. In: Defect and diffusion forum, vol. 75. 1991. p. 121-48.

[52] Lisiak K, Milnes A. Solid-State Electron 1975;18(6):533-40.

[53] Baldi L, Cerofolini G, Ferla G, Frigerio G. Phys Status Solidi (a) 1978;48(2):523-32. 